\title{
Social support in empathic online communities for older people
}

\author{
Ulrike Pfeil \\ Centre for $\mathrm{HCl}$ Design \\ City University \\ London, EC1 OHB \\ U.Pfeil-1@citv.ac.uk
}

\begin{abstract}
The goal of my $\mathrm{PhD}$ is to investigate how older people exchange social support in empathic online communities. This will be achieved through an in-depth investigation of online communities for older people. The results of my work will shed light on the characteristics of empathy exchanged among older people in online communities opposed to their offline communication. This is a valuable contribution to the research area of HCI, as it shows how empathic online communities can be used to support older people in their daily lives. I have published the preliminary findings of my work as a full paper at CHI 2007.
\end{abstract}

\section{Categories and Subject Descriptors}

H4.3. Information System Applications: Communication Applications; K4.2. Computers and society: Social issues

\section{General Terms}

Design

\section{Keywords}

Older people, online communities, empathy, support, communication, social interaction

\section{INTRODUCTION}

\subsection{Problem statement}

Between 2000 and 2004 the degree of internet usage by people aged 65 and older has increased by $47 \%$. Currently, $28 \%$ of older British people go online [4]. Similar numbers can be found in USA, as $22 \%$ of American older people use the internet and this figure is estimated to continue growing [3]. A lot of work has been done to establish guidelines and standards to make the internet accessible for older people. However, the focus has so far been mainly on making information on websites accessible. Does this account for all activities that can be performed online?

In recent years, activities on the internet expanded from mainly retrieving information to participating in virtual social settings, where people interact with each other to socialise [7] and/or to collaborate [6]. Empathic online communities are one such example where people meet online. They offer a place for

\section{(C) U. Pfeil}

2007 Published by the British Computer Society

Volume 2 Proceedings of the 21st BCS HCI Group

Conference HCI 2007, 3-7 September 2007, Lancaster

University, UK

Devina Ramduny-Ellis \& Dorothy Rachovides (Editors) people that experience a similar life situation to share information and to support each other [7].

However, little is known about how older people interact and socialise in online communities. How does the exchange of support among older people differ between online and offline settings? What are the motivations for older people to participate in online communities? How could online communities for older people be designed to encourage their participation and support them in their daily lives? To answer these questions, I am studying the characteristics and patterns of support in empathic online communities for older people.

\subsection{Aims and objectives}

The overall aim of my research is to study the facilitation of empathy and social support in online communities for older people. Online and offline empathic communication will first be investigated separately. Differences and similarities between the two will be highlighted. The acquired knowledge will then be applied in a detailed ethnographic study of an online community for older people. The following steps are proposed: I. Identify the characteristics of online and offline empathic communication and the social networks that evolve around it.

II. Investigate possible methods that allow gathering of the necessary data (e.g. virtual ethnography).

III. Based on the findings of objectives I. and II., develop a methodological framework for studying empathic online communities for older people.

IV. Apply the framework to study an online community for older people in detail. This includes the investigation of the content, the social network and the evolution of the online community over time.

\section{RELATED STUDIES}

Studies of empathic online communities have so far been mainly focused on health-related online communities for people suffering from an illness and/or for their caregivers. Findings show that factual information about the disease, practical tips about how to handle the situation, and emotional support are the major topics of online empathic communication [7]. People value to talk to others that are in a similar situation and turn to the online community for support when they face problems.

As older people often share a similar life situation (e.g. retirement) it is likely that they develop online communities that entail a high degree of emotional support. As social interaction correlates positively with the perceived well-being of older people [1], it is believed that participation in empathic online communities can prevent isolation and enhance the quality of life for older people. Furthermore, studies have shown that regular computer usage encourages older people to keep mentally and socially active [2]. 
Only few studies have so far investigated social interaction in online communities by older people. Wright [9] studied the exchange of social support within SeniorNet, an online community for older people. Findings show that valuing the community, giving advice based on one's own experiences and sharing life experiences are the major online community topics. Members value both, informational and emotional support [9]. The more time older people spend in online communities, the higher is their satisfaction with their received support and the larger is the number of people they are in contact with [8].

\section{COMPLETED WORK}

I have applied qualitative content analysis to messages of an online discussion board within SeniorNet to study the occurrence of empathy. Through an iterative process in which message postings were reduced to concepts and patterns, I developed a code scheme that captured the prevalent themes of the discussion. The findings were contrasted to characteristics of offline empathy. The work was published in a full paper at CHI 2007 [5] and another part of it is currently under review by the Universal Access in the Information Society journal.

Furthermore, Social Network Analysis (SNA) was performed with the data of the discussion board. SNA aims to understand the structure of relations between members of a social system that are characterised by information exchange between these members [10]. I applied SNA to investigate the impact of the communication content on the social network and relations between the participants of the online discussion board.

In order to investigate if the characteristics of online empathy are valid for a broader variety of online communities for older people, I generalised the code scheme across three additional discussion boards for older people with different topics. Furthermore, I conducted interviews with older people in order to capture their experiences of social support offline. I compared the findings with online support to see how older people's view of supports fits into the code scheme that was developed from the online discussion boards (see objective I).

\section{FUTURE WORK}

The findings from my completed work will be used to investigate the differences and commonalities of social support for older people in online and offline environments. The prestudies will conclude in a methodological framework that can be applied to study online communities for older people (see objective III). This framework will be used to study an online community for older people over a long period of time and indepth (see objective IV).

Virtual ethnography will be used to study the facilitation of empathy in an online community for older people. A multimethod triangulation will be applied, as different methods will be used to study the online community and the combination of the findings will allow for an in-depth investigation of the communication patterns and community structures of the online community for older people. The application of different methods in the pre-studies will help to judge their applicability in the main study (see objective II.). Methods that will be applied in this research include, but are not limited to:

I. Content analysis will be used to understand the components and characteristics of the content within an empathic online community for older people.

II. SNA will be applied to investigate the characteristics of the network that is developed through the communication and to spot and study key-members within the online community.
III. Query-based techniques will be used in order to gather experiences and opinions from older people. If necessary, interviews and questionnaires will be conducted online.

\section{FUTURE CONTRIBUTION}

The conclusions of my research will help to assess the opportunities and challenges of online communities for older people as a means of supporting them in their daily life. By clarifying how older people exchange social support in online communities, I will investigate in depth the components of online support and the network structure that develops around it. Investigating the advantages and problems of online communication for older people, my research will give insights in how the accessibility of the social aspect of the internet can be improved for this user group. This will contribute significantly to the analysis and evaluation of online communities and can also feed back into their design. Understanding the needs and preferences of older people concerning empathic online communication helps us to find technologies and concepts that support these. Thus, online communities that nurture supportive communication among older people can be designed more successfully.

\section{REFERENCES}

[1] Czaja, S.J., Guerrier, J.H., Nair, S.N., and Laudauer, T.K. Computer communication as an aid to independence to older adults. Behaviour and Information Technology, 12, 1993, 197-207.

[2] Eilers, M.L. Older adults and computer education: Not to have the world a closed door. International Journal of Technology and Aging, 2, 1989, 56-76.

[3] Fox, S. Older Americans and the Internet. Washington, DC: Pew Internet \& American Life Project, 2004.

[4] Office of Communication. Consumers and the communications market: 2006. Ofcom Consumer Panel, 2006.

[5] Pfeil, U. \& Zaphiris, P. Patterns of empathy in online communication. To appear in Proceedings of CHI 2007 the ACM Conference on Human Factors in Computing Systems (San Jose, CA, 28. April - 03. May 2007).

[6] Pfeil, U., Zaphiris, P., Ang C.S. (2006). Cultural Differences in Wiki Collaboration. Journal of Computer Mediated Communication, 12(1), article 5.

[7] Preece, J. \& Ghozati, K. Observations and Explorations of Empathy Online. In. R. R. Rice and J. E. Katz, The Internet and Health Communication: Experience and Expectations. Sage Publications Inc.: Thousand Oaks, 2001, 237-260.

[8] Wright, K. B. Computer-mediated support groups: An examination of relationships among social support, perceived stress, and coping strategies. Communication Quarterly, 47(4), 1999, 402-414.

[9] Wright, K. B. The communication of social support within an on-line community for older adults: A qualitative analysis of the SeniorNet community. Qualitative Research Reports in Communication, 1(2), 2000, 33-43.

[10] Zaphiris, P., Sarwar, R. (2006) Trends, Similarities and Differences in the Usage of Teen and Senior Public Online Newsgroups. ACM Transactions on Computer-Human Interaction (TOCHI), 13(3), 2006, 403-422. 